\title{
Effects of two alfalfa preparations with different particle sizes on the gastric mucosa in weanlings: alfalfa chaff versus alfalfa pellets
}

\author{
Sarah Vondran ${ }^{1}$, Monica Venner ${ }^{2}$ and Ingrid Vervuert ${ }^{1 *}$
}

\begin{abstract}
Background: Feeding alfalfa hay is often recommended for its buffering components, like protein and calcium, to prevent lesions of the gastric mucosa in horses. Until now, there has been no information regarding the influence of alfalfa particle size on the gastric mucosa. The aim of this study was to investigate the effects of feeding two alfalfa preparations with different particle sizes (alfalfa chaff vs alfalfa pellets) in comparison with grass hay on the gastric mucosa in weanling horses. We hypothesized that feeding a high proportion of fine alfalfa particles would negatively impact gastric mucosa and that feeding long alfalfa chaff would improve gastric mucosal health in weanlings.
\end{abstract}

Results: Before weaning, the prevalence of gastric mucosa lesions (one or more lesions considering all locations in the stomach) was $84.3 \%$; at 14 days after weaning, it was almost $100 \%$. Before and after weaning, most of the lesions were found at the greater curvature of the squamous mucosa and at the lesser curvature. After weaning, gastric mucosal lesions at the pylorus were significantly more severe in the group fed alfalfa chaff ( $p=0.002)$. In the other regions, no differences related to the feeding regimes were observed.

Conclusions: Feeding alfalfa failed to improve gastric mucosal lesion scores in weanlings. Furthermore, foals fed alfalfa chaff had higher lesion scores at the pylorus. Alfalfa leaves contain a superior protein source and high amounts of calcium and magnesium, providing extra nutritional advantages in growing horses. At this time, either traditional grass hay rations or grass hay with alfalfa pellets can be recommended.

Keywords: Squamous, Glandular, Stomach, Gastric lesions, Horse

\section{Background}

Gastric ulceration is commonly identified in horses and foals. The prevalence of gastric ulcers in Thoroughbred racehorses is estimated to be $>80 \%$ in the squamous mucosa [1]. In weanlings it ranges between 32 and $94 \%$ $[2,3]$. Risk factors for gastric mucosa lesions, specifically for equine squamous gastric ulcer disease, are stall confinement, strenuous exercise, transport stress in adult horses (as reviewed by Andrews and others [4]), and the weaning process in foals $[2,3]$. Nonsteroidal

\footnotetext{
* Correspondence: ingrid.vervuert@vetmed.uni-leipzig.de 'Institute of Animal Nutrition, Nutrition Diseases and Dietetics, Faculty of Veterinary Medicine, University of Leipzig, D-04103 Leipzig, Germany

Full list of author information is available at the end of the article
}

anti-inflammatory drugs have been demonstrated to be a risk factor for the equine glandular region in adult horses and foals $[5,6]$.

The relationship between feeding and gastric mucosal health has been demonstrated. Dietary factors that may effect squamous gastric mucosa in horses include buffering substances [7], the level of starch intake [8], or the type and daily amount of food $[8,9]$. Furthermore, the particle size of the diet appears to be a factor in glandular gastric mucosa [2]. In foals, feeding alfalfa chaff resulted in glandular mucosal lesions, which may have been related to mechanical irritation [2]. Furthermore, no favorable effect was found on the squamous mucosa in weanlings. However, other authors observed beneficial 
effects of feeding alfalfa hay on the squamous mucosa in foals [10] and adult horses [7]. In pigs fed a diet of finely ground pellets, the squamous gastric ulcer score was significantly higher than for those fed a diet of larger particles [11]. Furthermore, feeding a coarse ground feed reduced mucosa lesions of the pars oesophagea in growing pigs [12].

The aim of this study was to investigate the effects of feeding two alfalfa preparations with different particle sizes (alfalfa chaff vs alfalfa pellets) in comparison with grass hay on the gastric mucosa in weanling horses. We hypothesized that feeding a high proportion of fine particles (alfalfa pellets) would negatively impact gastric mucosa in foals and that foals receiving alfalfa chaff would have better gastric mucosal lesion scores.

\section{Results}

None of the foals in the study demonstrated any clinical signs commonly associated with the presence of gastric ulcers such as colic, inappetence, or depression, as reviewed by Andrews and others [4].

The daily average consumption of grass hay per foal was $4.3 \mathrm{~kg}$ in the alfalfa chaff group, $5.0 \mathrm{~kg}$ in the alfalfa pellets group, and $8.3 \mathrm{~kg}$ in the grass hay group (Table 1). In addition to the grass hay intake, the mean daily feed intake $( \pm$ SD) was $5.95 \pm 0.13 \mathrm{~kg}$ in the alfalfa chaff group, $5.47 \pm 0.18 \mathrm{~kg}$ in the alfalfa pellets group, and $3.66 \mathrm{~kg}$ in the hay group.

In the alfalfa chaff group, $91 \%$ of alfalfa chaff particles were longer than $2 \mathrm{~mm}$; in the alfalfa pellets group, $60 \%$ of alfalfa pellets particles were smaller than $0.25 \mathrm{~mm}$ (Table 2).

Mean ( \pm SD) body weight increased in all groups (alfalfa chaff group: $4.8 \pm 1.9 \%$; alfalfa pellets group: $5.5 \pm$ $2.5 \%$; hay group: $4.3 \pm 2.3 \%)$. There was no significant difference $(p=0.49)$ in weight gain between groups.

Before weaning $(T=0)$, the prevalence of gastric mucosa lesions (one or more lesions considering all locations in the stomach) was $84.3 \%$; at 14 days after weaning $(T=16)$, it was almost $100 \%$. Before and after weaning, most of the lesions were found at the greater curvature of the squamous mucosa and at the lesser curvature (Table 3, Figs. 1, 2, 3, 4 and 5).

\section{Effect of weaning on gastric mucosa}

Only very few foals had gastric mucosa lesions in the dorsal squamous fundus before and after weaning in the three diet groups. In the squamous region of the greater curvature, the median lesion score was $1(0 / 1)$ before and $0(0 / 2)$ after weaning in the hay group $(p=0.78), 0$ $(0 / 1)$ before and $0(0 / 1)$ after weaning in the alfalfa chaff group $(p=0.21)$, and $1(0 / 2)$ before and $2(1 / 2)$ after weaning in the alfalfa pellets group $(p=0.17)$ (Fig. 1). In the squamous region of the lesser curvature, the median lesion score increased from $1(0 / 2)$ before to $2(1.75 / 2)$ after weaning in the hay group $(p=0.03)$, increased from $1(0 / 2)$ before to $2(1 / 3)$ after weaning in the alfalfa chaff group $(p=0.02)$, and was $2(1 / 2)$ before and $2(0 / 3)$ after weaning in the alfalfa pellets group ( $p=0.14)$ (Fig. 2$)$.

In the glandular region of the greater curvature, the median lesion score was $0(0 / 1)$ before and $0(0 / 1)$ after weaning in the hay group $(p=1), 0(0 / 0)$ before and 0 $(0 / 0)$ after weaning in the alfalfa chaff group $(p=0.48)$, and $0(0 / 1)$ before and $0(0 / 0)$ after weaning in the alfalfa pellets group $(p=0.35)$ (Fig. 3$)$. In the antrum, the median lesion score was $0(0 / 0)$ before and $0(0 / 0)$ after weaning in the hay group $(p=0.18), 0(0 / 0)$ before and 0 $(0 / 1)$ after weaning in the alfalfa chaff group $(p=0.01)$, and $0(0 / 0)$ before and $0(0 / 1)$ after weaning in the alfalfa pellets group ( $p=0.03$ ) (Fig. 4). At the pylorus, the median lesion score was $0(0 / 0)$ before and $0(0 / 0)$ after weaning in the hay group $(p=1), 0(0 / 0)$ before and 1 $(0 / 2)$ after weaning in the alfalfa chaff group $(p<0.001)$, and $0(0 / 0)$ before and $0(0 / 0)$ after weaning in the alfalfa pellets group $(p=0.56)$ (Fig. 5).

\section{Effect of diet on gastric mucosa}

Before weaning $(T=0)$, the gastroscopic findings of each region did not differ significantly between the three diet groups (Table 3$)$. After weaning $(T=16)$, gastric mucosal lesions at the pylorus were significantly more severe in the group fed alfalfa chaff $(p=0.002)$ (Fig. 5). In the other regions, no differences related to the feeding regimes were observed.

\section{Discussion}

Various methods have been used to induce gastric ulcers. In this study we used the weaning process as a

Table 1 Mean ( \pm SD) daily dry matter and nutrient intake for each foal according to diet

\begin{tabular}{|c|c|c|c|c|c|c|c|c|c|}
\hline Diet & DM & Ash & $C P$ & $\mathrm{CF}$ & NDF & Starch & $\mathrm{Ca}$ & $P$ & $\mathrm{Mg}$ \\
\hline$\overline{A C}$ & $9383 \pm 120$ & $461 \pm 9$ & $1190 \pm 19.5$ & $2978 \pm 54$ & $5265 \pm 75$ & $1410 \pm 7$ & $82 \pm 1.6$ & $27 \pm 0.4$ & $\overline{16 \pm 0.2}$ \\
\hline AP & $9798 \pm 167$ & $608 \pm 21$ & $1232 \pm 31$ & $2937 \pm 54$ & $5585 \pm 79$ & $1410 \pm 9.5$ & $86 \pm 4$ & $26 \pm 0.4$ & $16 \pm 0.3$ \\
\hline $\mathrm{HA}$ & 10,800 & 457 & 1270 & 3286 & 6729 & 1404 & 89 & 29 & 20 \\
\hline
\end{tabular}


Table 2 Percentages of different particle sizes of alfalfa pellets and alfalfa chaff

\begin{tabular}{llllll}
\hline Feedstuff & $>2 \mathrm{~mm}$ & $>1 \mathrm{~mm}$ & $>0.5 \mathrm{~mm}$ & $>0.25 \mathrm{~mm}$ & $<0.25 \mathrm{~mm}$ \\
\hline Alfalfa chaff & $90.8 \%$ & $6.62 \%$ & $1.94 \%$ & $0.28 \%$ & $0.31 \%$ \\
Alfalfa pellets & $4.63 \%$ & $6.95 \%$ & $12.4 \%$ & $16.1 \%$ & $59.9 \%$ \\
\hline
\end{tabular}

model to induce gastric ulcers in foals to determine the effects of feeding. Previous studies have shown that the weaning process is a stressful event in a foal's life and may increase gastric lesions. Dahlkamp and others [3] reported that ulcer scores of the squamous region, as examined by gastroscopy, increased from $48 \%$ before weaning to $78 \% 2$ weeks after weaning. This study revealed an initial prevalence of gastric lesions in glandular and squamous regions of $84.3 \%$ prior to weaning. The changes in feeding and housing management 1 week before weaning may have resulted in high gastric lesion scores. The introduction to new stables and housing groups was performed to ensure standardized experimental conditions.

The aim of the study was to evaluate the impact of feeding different particle sizes to weanlings. Gastric findings of each region of the stomach were scored separately because we assumed that diet regime might have various influences on the gastric mucosa of different regions.

One food source recommended to prevent gastric lesions in horses is alfalfa hay. Nadeau and others [7] found a lower incidence of gastric lesions in horses fed alfalfa hay. The reason for the beneficial effects of feeding alfalfa is related to its buffering components, like protein and calcium. High calcium intake reduced the basal $\mathrm{HCl}$ secretion in rats. This effect was suspected to be a result of higher extracellular and intracellular calcium concentrations in parietal and G cells. Higher extracellular and intracellular calcium concentrations may lower the cAMP concentration, thus reducing the production of $\mathrm{HCl}$ [13]. Exposure of the equine gastric mucosa to $\mathrm{HCl}$ and short-chain fatty acids significantly decreased sodium transport of the cells. The addition of calcium carbonate decreased the sodium transport to baseline [14]. From these results, the authors proposed that calcium has a protective effect in the development

Table 3 Grading of the different stomach regions before weaning for the different feeding protocols

\begin{tabular}{|c|c|c|c|c|c|c|}
\hline \multirow[t]{2}{*}{ Diet } & \multicolumn{3}{|c|}{ Squamous region } & \multicolumn{3}{|c|}{ Glandular region } \\
\hline & $\begin{array}{l}\text { Dorsal } \\
\text { fundus }\end{array}$ & $\begin{array}{l}\text { Lesser } \\
\text { curvature }\end{array}$ & $\begin{array}{l}\text { Greater } \\
\text { curvature }\end{array}$ & $\begin{array}{l}\text { Greater } \\
\text { curvature }\end{array}$ & Antrum & Pylorus \\
\hline$A C$ & $0(0 / 0)$ & $1(0 / 2)$ & $0(0 / 1)$ & $0(0 / 0)$ & $0(0 / 0)$ & $0(0 / 0)$ \\
\hline AP & $0(0 / 0)$ & $2(1 / 2)$ & $1(0 / 2)$ & $0(0 / 1)$ & $0(0 / 0)$ & $0(0 / 0)$ \\
\hline $\mathrm{HA}$ & $0(0 / 0)$ & $1(0 / 2)$ & $1(0 / 1)$ & $0(0 / 1)$ & $0(0 / 0)$ & $0(0 / 0)$ \\
\hline$p$ value & 0.39 & 0.20 & 0.18 & 0.31 & 0.25 & 0.94 \\
\hline
\end{tabular}

Data expressed as median (25th/75th percentiles) of gastric lesions. Nadeau and others [7] found significantly lower scores of the squamous mucosa in horses fed an alfalfa hay/grain diet compared to horses fed a brome hay diet. The authors concluded that high amounts of protein and the quality of the protein may have buffering effects in the stomach, as previously seen in cattle [15].

Alfalfa is believed to have beneficial effects on gastric mucosa by buffering gastric $\mathrm{pH}$ because it contains large amounts of calcium, magnesium, and protein. In the present study, calcium and protein intake were approximately equal among the different feeding groups (Table 1), but particle size between the two alfalfa preparations was different. Former studies have demonstrated the impact of the particle size on the stomach mucosa in different species. Saliva production is related to the particle structure of a diet, and saliva has a buffering effect due to its potassium, chloride, and bicarbonate [16]. For example, feeding $1 \mathrm{~kg}$ of hay results in 3 to $6 \mathrm{~L}$ of saliva production and feeding $1 \mathrm{~kg}$ of grain results in 1 to $1.7 \mathrm{~L}$ of saliva production in adult horses [17]. The concentration of bicarbonate in saliva may impact stomach $\mathrm{pH}$ [18]. These effects may explain the lower gastric lesion scores in weanlings fed hay in our study. However, lesion scores of weanlings in the alfalfa pellets group were not significantly different from those in the hay group. It is possible that although the foals fed alfalfa pellets may have produced less saliva, the high-quality protein in the alfalfa may have resulted in ulcer scores similar to those in the hay group.

Foals fed alfalfa chaff had higher ulcer scores at the pylorus than those fed alfalfa pellets or hay. These results were surprising because alfalfa chaff has been suggested to be associated with higher saliva production due to the more intensive chewing involved; increased saliva flow is known to have a buffering effect on the stomach. The findings in the alfalfa chaff group were similar to those of Fedtke and others [2]. These authors noted that feeding alfalfa chaff resulted in significantly greater ulcer scores at the pylorus following weaning. They speculated that the pyloric ulcers might be related to the small particles of the alfalfa chaff, similar to results obtained in swine [2]. Mößeler and others [11] fed pigs four different diets with different grinding intensities and different physical forms (pellets vs meal) for 3 days. Animals were examined post-mortem. Samples of the frozen gastric contents were taken from 15 standardized locations of the stomach. Mößeler and others [11] demonstrated that a finely ground pellet diet resulted in more liquid gastric contents and that $\mathrm{pH}$ values were similar in all regions of the stomach (mean \pm SD $\mathrm{pH}$ difference between the regions: $0.175 \pm 0.140$ ). In contrast, a coarsely ground diet resulted in stratification of the gastric chyme content, with a $\mathrm{pH}$ difference of $2.22 \pm 1.04$ (mean $\pm \mathrm{SD}$ ). In the squamous region, the gastric ulcers score was significantly higher in pigs fed a 


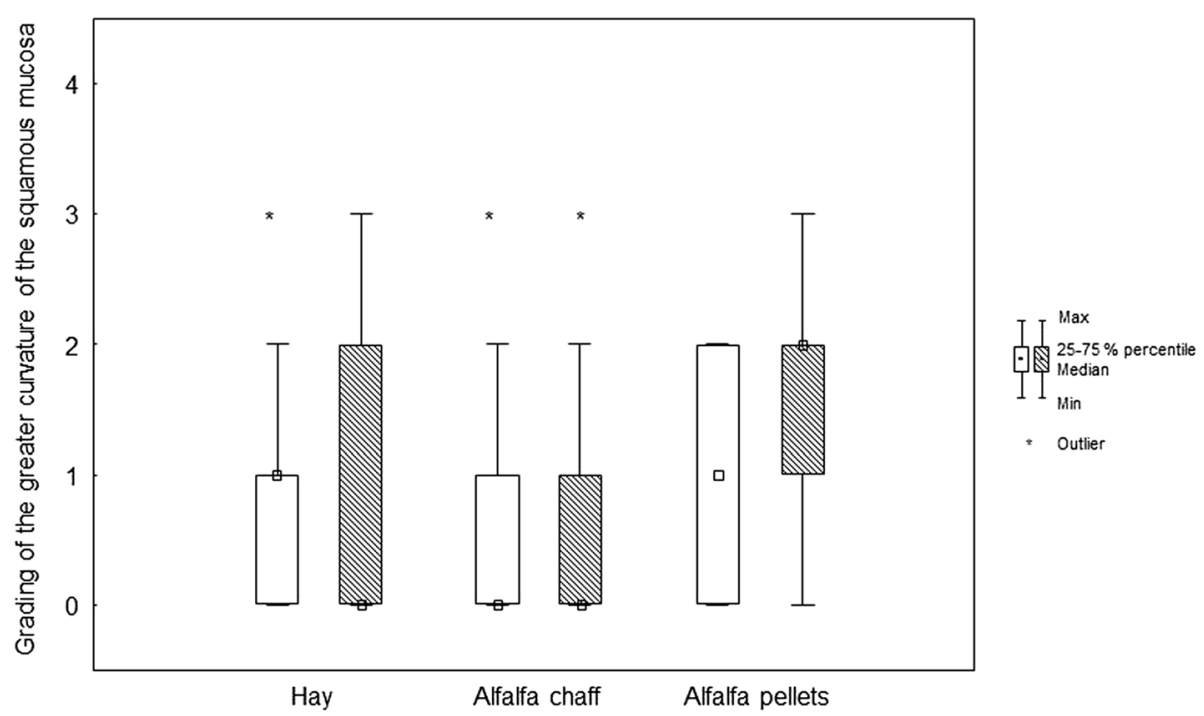

Fig. 1 Box (median) and whisker (25th/75th percentiles) plots of lesions grades for the greater curvature of the squamous mucosa before and after weaning for the different feeding protocols (white plots before weaning; striped plots after weaning)

finely ground pellet diet in comparison with pigs fed a coarsely ground diet without pellets [19]. All studies performed on pigs focused on the squamous region, which is the most common region for development of gastric ulceration in pigs [20]. Pigs fed a diet of finely ground pellets also showed greater histological evidence of inflammation compared to pigs fed other diets [21].

However, our results differed from those noted in pigs. Higher ulcer scores were observed after feeding alfalfa chaff compared to hay or alfalfa pellets. In our study alfalfa pellets with a particle size smaller than $1 \mathrm{~mm}$ did not induce pyloric lesions. This might be due to the fact that all foals in our study had free access to hay and straw bedding as sources of food. This factor may have masked the negative effects of fine particles in the diet. However, due to the large sample size number, we could not provide individual feeding, but due to the very close monitoring of the foals, we can ensure a similar feed intake within the groups and between the different diets.

It is possible that the harsh acanthous structure of alfalfa chaff may cause mechanical injury at the pylorus. The pyloric region is an area of the stomach with high motility. We assume that the movement of the alfalfa stems may excoriate the mucosa during passage. This

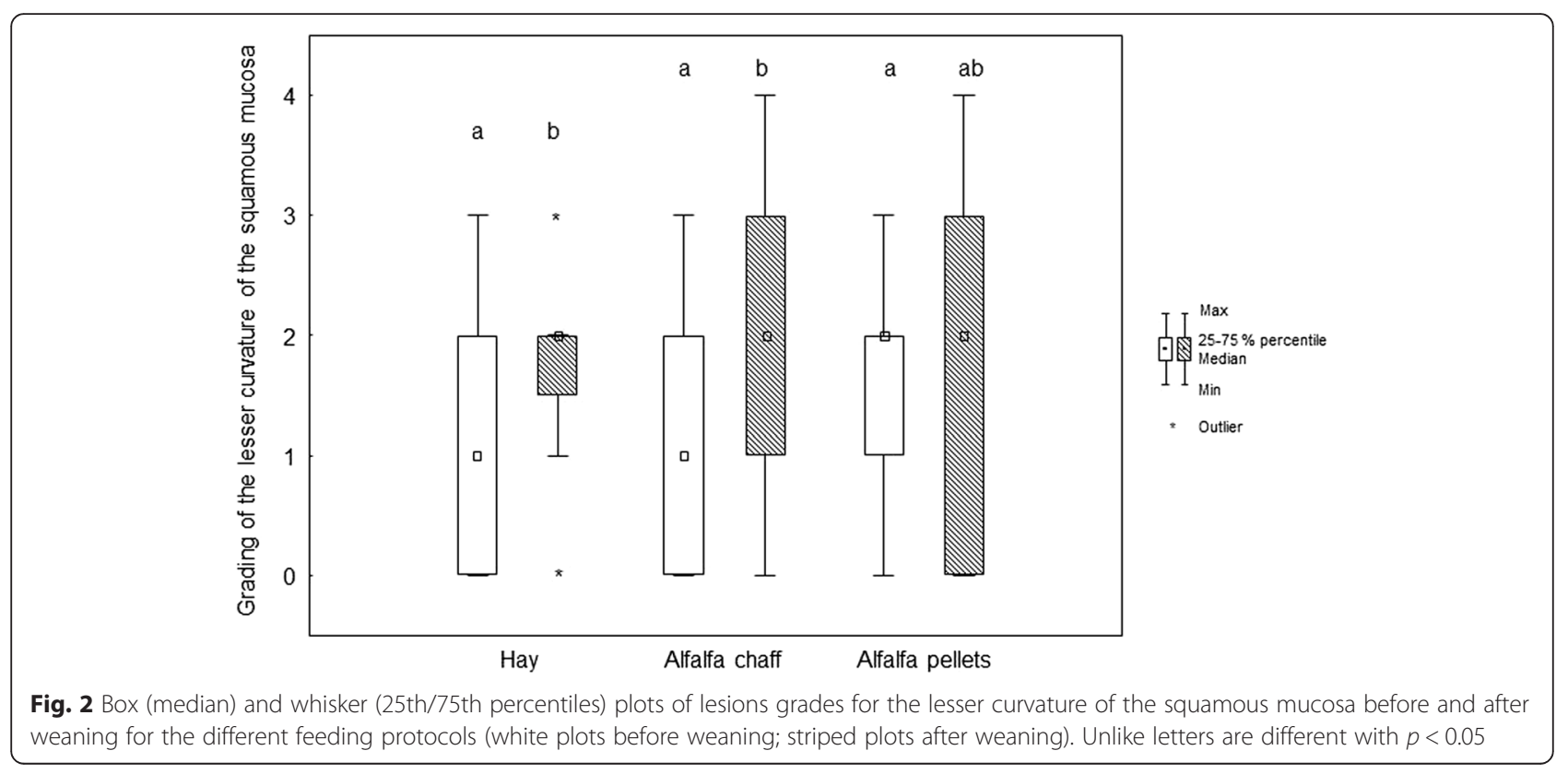




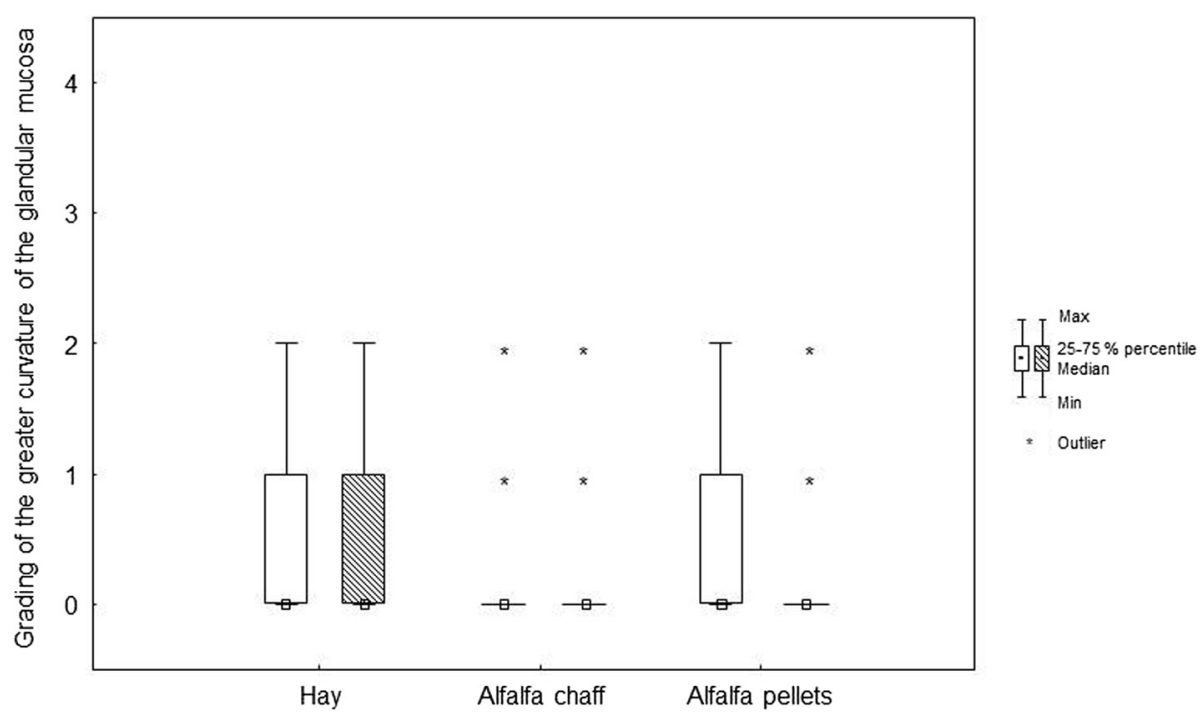

Fig. 3 Box (median) and whisker (25th/75th percentiles) plots of lesions grades for the greater curvature of the glandular mucosa before and after weaning for the different feeding protocols (white plots before weaning; striped plots after weaning)

initial injury of the glandular mucosa might leave the pylorus more vulnerable to the insults of short-chain fatty acids, hydrochloric acid, and/or bile salts. Pyloric lesions are of particular clinical concern because damage to the pylorus may result in pyloric stenosis with delayed gastric emptying [22]. However, further studies are required to determine whether feeding the whole alfalfa plant may result in similar findings.

\section{Conclusions}

Foals fed alfalfa chaff had higher lesion scores at the pylorus. These findings stress the importance of scoring all gastric regions separately. Furthermore, in the past, particle size has been neglected in equine nutrition; however, our data seem to show this might be an issue in the occurrence of pyloric lesions. It remains unclear whether the mucosa injuries can be observed only in weanlings during the stressful weaning process as a result of impaired mucosal defence or whether the damage can also be induced in adult horses. Nevertheless, alfalfa leaves contain a superior protein source and high amounts of calcium and magnesium [23], providing extra nutritional advantages in growing horses. At this time, either traditional grass hay rations or grass hay with alfalfa pellets can be recommended.

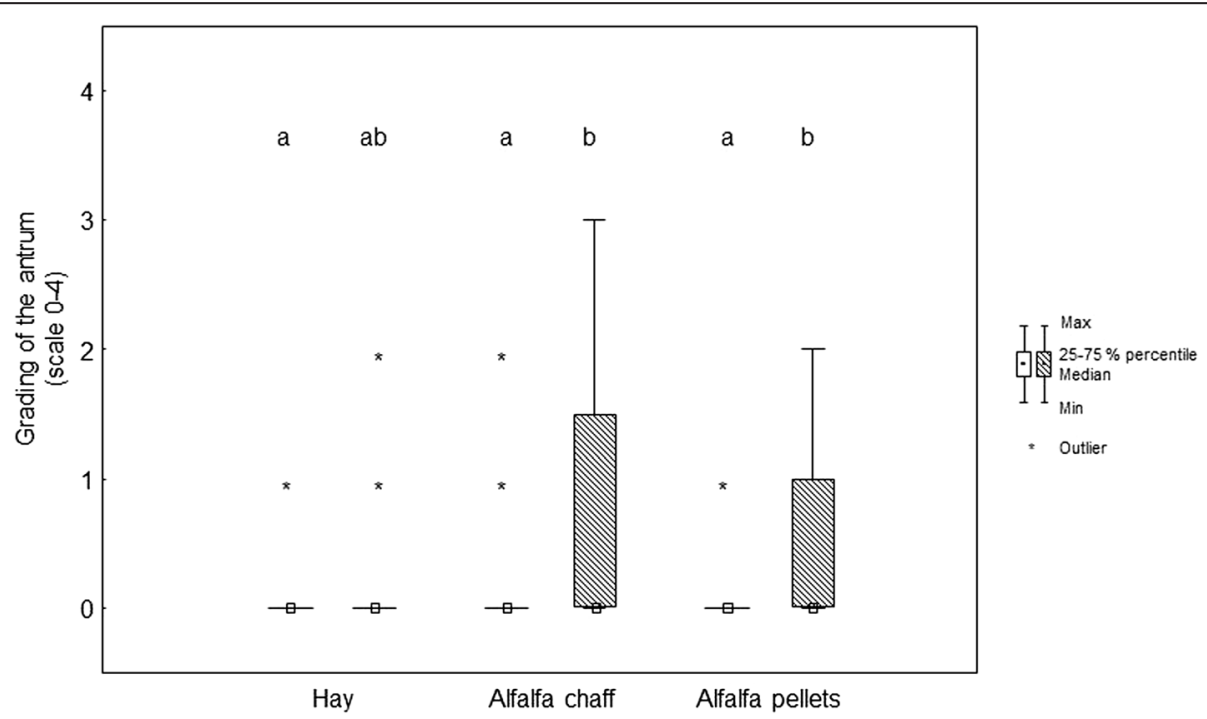

Fig. 4 Box (median) and whisker (25th/75th percentiles) plots of lesions grades for the antrum before and after weaning for the different feeding protocols (white plots before weaning; striped plots after weaning). Unlike letters are different with $p<0.05$ 


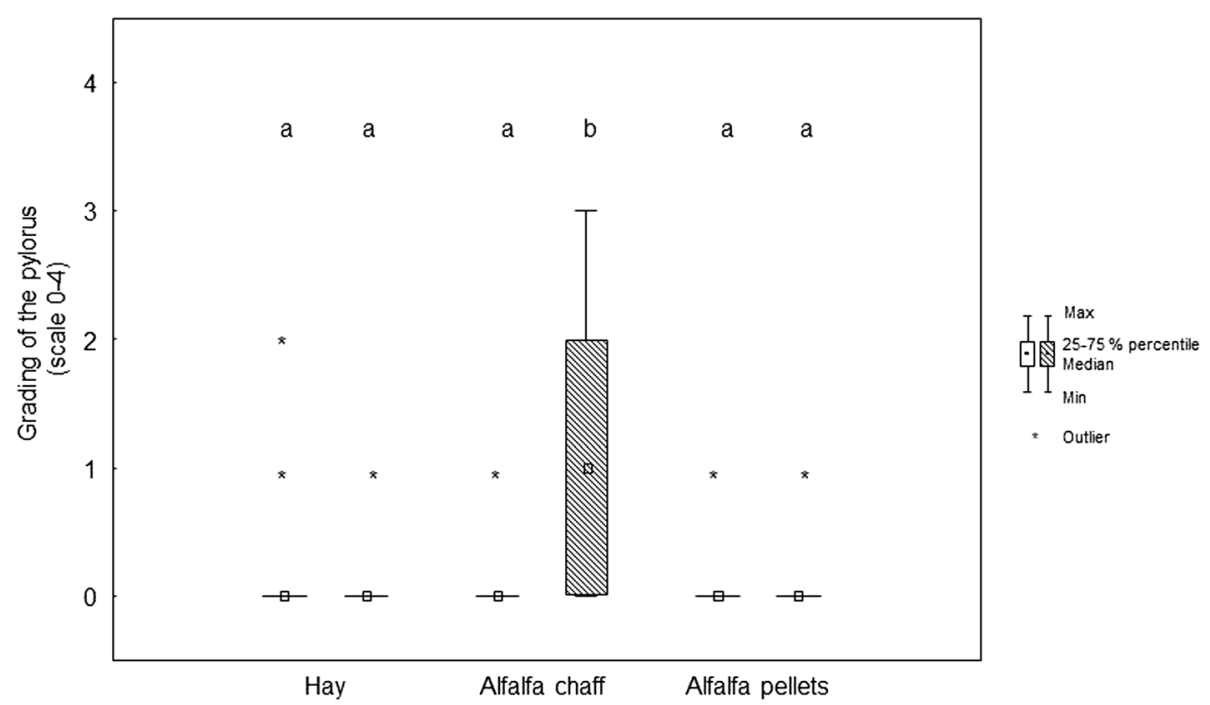

Fig. 5 Box (median) and whisker (25th/75th percentiles) plots of lesions grades for the pylorus before and after weaning for the different feeding protocols (white plots before weaning; striped plots after weaning). Unlike letters are different with $p<0.05$

\section{Methods}

\section{Animals}

Seventy warmblood foals (39 males, 31 females), 164 to 234 days of age, with a mean body weight $( \pm$ SD) of 256 $\pm 24 \mathrm{~kg}$ were included in the study. All foals were born and raised at a stud farm in Germany. Inclusion criteria for the foals were minimum age of 150 days, no findings at clinical examination and physiological white blood cell count, and no medication 10 days prior to initiation of the study. At $\mathrm{T}=-7$, the foals and mares were moved into covered barns with straw bedding and free access to concrete runs. Mares and foals were fed a total mixed ration (TMR) once per day (approximately $13 \mathrm{~kg}$ per mare and foal per day) to meet or exceed the energy and nutrient requirements of the mares. The TMR comprised $3 \mathrm{~kg}$ corn silage, $6 \mathrm{~kg}$ grass silage, $2 \mathrm{~kg}$ oats, $0.5 \mathrm{~kg}$ straw, $0.3 \mathrm{~kg}$ soybean meal, $0.05 \mathrm{~kg}$ of a commercial mineral vitamin supplement (Vilomix Biolex; Deutsche Vilomix Tierernährung $\mathrm{GmbH}$, Neuenkirchen-Vörden, Germany), and $0.04 \mathrm{~kg} \mathrm{CaCO}$. Horses had access to grass hay and water ad libitum.

Foals were weaned at $T=0$ and grouped with respect to their dietary treatment. All groups were housed as described. Sample size calculation was performed with PASS 2002 (NCSS, Statistical Software). The required sample size was 15 foals. To ensure a proper sample size at the end of study, and taking into account that some foals might have to be excluded during the study period due to reasons not related to the study design, we increased the groups to up to 25 foals. During the study we had to exclude five foals because of orthopedic injuries. Foals were allocated to each group according to the homogenous distribution of gastric findings at the first gastroscopy.
During the study period the foals were monitored three times daily by a veterinarian for signs of discomfort, depression, inappetence, bruxism, or colic.

\section{Feeding}

Before weaning, foals were introduced to their respective diets from $T=-3$ to $T=0$ (day of weaning) without being separated from their dam.

After weaning, the foals were separated from their dam and allocated to the three diets. In the alfalfa chaff group $(n=25)$, foals were fed daily with $3 \mathrm{~kg}$ alfalfa chaff per foal and had free access to grass hay. Additionally, foals were offered $2.7 \mathrm{~kg}$ oats, $240 \mathrm{~g}$ soybean meal, $70 \mathrm{~g}$ calcium oxide and $40 \mathrm{~g}$ of a commercial trace element mixture (see above) mixed with the alfalfa chaff. To ensure uniform consumption, alfalfa chaff was mixed with $400 \mathrm{ml}$ of water for each foal to bind alfalfa chaff to the other feed components.

In the alfalfa pellets group $(n=21)$, each foal was fed daily with $3 \mathrm{~kg}$ alfalfa pellets composed of finely ground alfalfa leaves. Additionally, each foal was fed daily with $2.7 \mathrm{~kg}$ oats and $40 \mathrm{~g}$ of a commercial trace element mixture (see above) and had free access to grass hay. The alfalfa pellets were mixed with oats and the commercial trace element mixture.

The hay group $(n=24)$ had free access to grass hay and received $3 \mathrm{~kg}$ oats, $0.5 \mathrm{~kg}$ soybean meal, $120 \mathrm{~g}$ $\mathrm{CaCO}_{3}$ and $40 \mathrm{~g}$ of a commercial trace element mixture (see above).

Each diet was standardized to supply a similar nutrient intake per day in each feeding group. The feed was offered in two equal portions twice daily (7:00 AM and 3:30 PM) in a continuous trough providing enough 
room for each foal. Feed intake was monitored several times daily and remaining feed was weighed after $24 \mathrm{~h}$. In total, the different diets were fed for 16 days after the weaning process. The nutrient intake is summarized in Table 1.

\section{Gastroscopy}

A gastroscopy with a flexible gastroscope (Karl Storz, Tuttlingen, Germany) with a working length of $3 \mathrm{~m}$ was performed immediately prior to weaning $(T=0)$ and again after the feeding period of 16 days $(T=16)$. Prior to gastroscopy, foals were fasted by using muzzles for 9 to $12 \mathrm{~h}$, but they had water ad libitum. The foals were sedated with $0.02 \mathrm{mg} / \mathrm{kg}$ body weight intravenous detomidinhydrochloride (Cepesedan ${ }^{\circ}$; CP Pharma, Burgdorf, Germany). The stomach was insufflated with air until the mucosal folds vanished. The following regions of the stomach were evaluated separately: dorsal squamous fundus; lesser curvature; greater curvature of the squamous region; greater curvature of the glandular region; antrum; and pylorus. Each region and mucosal type was given a score from 0 to 4 . Squamous mucosa was scored according to a proposal of the European College of Equine Internal Medicine [24] (Table 4). Glandular gastric mucosa including the antrum and pylorus was evaluated according to a modified scoring system (Table 5). Gastric mucosa was evaluated during gastroscopy by the same blinded and experienced investigator (MV).

\section{Scaling}

Body weight was measured by an electronic weight scale (Müller, Jagstzell, Germany) immediately before each gastroscopy. Feedstuffs were weighed using an automatic scale (Beurer, Ulm, Germany and Waagen-Schmitt GmbH, Hamburg, Germany).

\section{Nutrient analysis}

Dry matter (DM) was determined after oven-drying $\left(103{ }^{\circ} \mathrm{C}\right)$ to a constant mass (Table 6). Crude ash was measured by ashing the feeds in a muffle furnace $(6 \mathrm{~h}$, $600^{\circ} \mathrm{C}$ ) [25]. Starch content was estimated polarimetrically (Polartronic E; Schmidt and Haensch, Berlin, Germany).

Table 4 Scoring system of the squamous regions of the equine stomach. Adapted from the proposal of the European College of Equine Internal Medicine [24]

\begin{tabular}{ll}
\hline Grade & Characteristics \\
\hline 0 & Epithelium intact and no appearance of hyperkeratosis \\
1 & Mucosa intact, but areas of hyperkeratosis \\
2 & Small, single or multifocal lesions \\
3 & Large single or extensive superficial lesions \\
4 & Extensive lesions with areas of apparent deep ulceration \\
\hline
\end{tabular}

Table 5 Scoring system of the glandular regions including the antrum and pylorus of the equine stomach

\begin{tabular}{ll}
\hline Grade & Characteristics \\
\hline 0 & $\begin{array}{l}\text { Epithelium intact and no appearance of hyperemia (reddening) } \\
\text { or fibrinosupperative areas }\end{array}$ \\
1 & $\begin{array}{l}\text { Intact flat mucosa, but with small single or multifocal areas of } \\
\text { reddening }\end{array}$ \\
2 & $\begin{array}{l}\text { Raised mucosa with large single or multifocal areas of reddening } \\
\text { or fibrinosupperative areas, no signs of bleeding }\end{array}$ \\
3 & $\quad \begin{array}{l}\text { Raised mucosa with hemorrhagic and fibrinosupperative areas } \\
4\end{array}$ \\
\hline
\end{tabular}

Sugar contents (glucose and sucrose) were determined by the Luff Schoorl method. Crude nutrients were assayed by the Weende system [25]. Neutral detergent fiber was analyzed by the Fibertec ${ }^{\circ}$ (Tectator, Rellingen, Germany) [26].

\section{Sieving}

To determine particle sizes, $50 \mathrm{~g}$ of alfalfa pellets were soaked with $1 \mathrm{~L}$ water for $24 \mathrm{~h}$ prior to sieving. Samples were sieved for 5 min with an extrusion of $1.5 \mathrm{~mm}$ and running water. Samples were dried $\left(60^{\circ} \mathrm{C}\right)$ before weighing. Fifty grams of dry alfalfa chaff were sieved for $5 \mathrm{~min}$ with an extrusion of $1 \mathrm{~mm}$. Sizes of the sieves were $2 \mathrm{~mm}, 1 \mathrm{~mm}, 0.5 \mathrm{~mm}$, and $0.25 \mathrm{~mm}$.

\section{Statistical analysis}

Statistical analysis was performed using a statistical software program (STATISTIKA, StatSoft). Body weight was analyzed for normal distribution by the Shapiro-Wilk W test. Stomach scores were calculated using medians, $25^{\text {th }}$ and $75^{\text {th }}$ percentiles, and ranges. The Wilcoxon signed rank test was used to compare gastroscopic scores within a group before and after weaning. Kruskal-Wallis ANOVA was performed to compare the gastroscopic scores between the treatment groups. A value of $p<0.05$ was considered significant.

Table $\mathbf{6}$ Chemical composition of feed

\begin{tabular}{llllll}
\hline & & Alfalfa chaff & Alfalfa pellets & Hay & Oats \\
\hline Ash & g/kg DM & 71 & 117 & 45 & 26 \\
CP & g/kg DM & 150 & 172 & 95 & 123 \\
CF & g/kg DM & 412 & 302 & 372 & 132 \\
NDF & g/kg DM & 578 & 441 & 732 & 355 \\
Ca & g/kg DM & 12.3 & 20.9 & 5.2 & 1.2 \\
$P$ & g/kg DM & 2.74 & 2.3 & 1.8 & 4.6 \\
Mg & g/kg DM & 1.65 & 1.8 & 1.7 & 1.7 \\
\hline
\end{tabular}

Ca calcium, CF crude fiber, $C P$ crude protein, $D M$ dry matter, NFE nitrogen-free extractives, $M g$ magnesium, $P$ phosphorus 


\section{Abbreviations}

$\mathrm{DM}$, dry matter; Fig, figure; $\mathrm{HCl}$, hydrochloric cid; L, liter; SD, standard deviation; T, time point; TMR, total mixed ration

\section{Acknowledgments}

The authors acknowledge support from German Research Foundation (DFG) and University of Leipzig within the program of Open Access Publishing.

\section{Funding}

Not applicable.

\section{Availability of data and materials}

All data supporting our findings are included in the manuscript.

\section{Authors' contributions}

SV carried out the feeding of the foals and participated in the gastroscopies, and helped to draft the manuscript. MV carried out the gastroscopies, and participated in its design and drafted the manuscript. IV designed the study and performed the statistical analysis and drafted the manuscript. All authors read and approved the final manuscript.

\section{Competing interests}

The authors declare that they have no competing interests.

\section{Consent for publication}

Not applicable.

\section{Ethics approval and consent to participate}

The project was approved by the Ethics Committee for Animal Rights Protection of the District government in Rostock (7221.3-1-045/14), in accordance with German legislation for animal rights and welfare. All foals were owned by one stud farm owner (Gestüt Lewitz). The owner was informed about the experimental protocol and full permission was given to carry out the study.

\section{Author details}

'Institute of Animal Nutrition, Nutrition Diseases and Dietetics, Faculty of Veterinary Medicine, University of Leipzig, D-04103 Leipzig, Germany. ${ }^{2}$ Equine Veterinary Clinic, D-38162 Destedt, Germany.

\section{Received: 3 November 2015 Accepted: 7 June 2016}

Published online: 14 June 2016

\section{References}

1. Vatistas NJ, Snyder JR, Carlson G, Johnson B, Arthu RM, Thurmond M, Zhou H, Lloyd KLK. Cross-sectional study of gastric ulcers of the squamous mucosa in thoroughbred racehorses. Equine Vet J. 1999;31:34-9.

2. Fedtke A, Pfaff M, Volquardsen J, Venner M, Vervuert I. Effects of alfalfa chaff on gastric mucosa in weanling foals. Pferdeheilkunde. 2015;6:596-602

3. Dahlkamp M, Feige $K$, Venner $M$. Incidence of gastric ulcers in weanling foals and the treatment with omeprazole. Pferdeheilkunde. 2012;28:561-9.

4. Andrews F, Bernard W, Byars D, Cohen N, Divers T, MacAllister C, McGladdery A, Merritt A, Murray M, Orisini J, Snyder J, Vatistas N. Recommendations for the diagnosis and treatment of equine gastric ulcer syndrome (EGUS). Equine Vet Educ. 1999;11:262-72.

5. Monreal L, Sabaté D, Segura D, Mayós I, Homedes J. Lower gastric ulcerogenic effect of suxibuzone compared to phenylbutazone when administered orally to horses. Res Vet Sci. 2004:26:145-9.

6. Meschter CL, Gilbert M, Krook L, Maylin G, Corradino R. The effects of phenylbutazone on the morphology and prostaglandin concentrations of the pyloric mucosa of the equine stomach. Vet Pathol. 1990;27:244-53.

7. Nadeau JA, Andrews FM, Mathew AG, Argenzio RA, Blackford JT, Sohtell M, Saxton AM. Evaluation of diet as a cause of gastric ulcers in horses. Am J. Vet Res. 2000;61:784-90.

8. Luthersson N, Nielsen $\mathrm{KH}$, Harris P, Parkin TD. Risk factors associated with equine gastric ulceration syndrome (EGUS) in 201 horses in Denmark. Equine Vet J. 2009:41:625-30

9. Coenen M, Kienzle E, Vervuert I, Zeyner A. Recent German developments in the formulation of energy and nutrient requirements in horses and the resulting feeding recommendations. J Equine Vet Sci. 2011;31:219-29.
10. Lybbert TC. Gastric ulcer syndrome in exercising horses fed different types of hay [master thesis]. Texas: A\&M University; 2007.

11. Mößeler A, Köttendorf S, Große Liesner V, Kamphues J. Impact of diets' physical form (particle size; meal/pelleted) on the milieu within the stomach content (dry matter content, $\mathrm{pH}$, chloride concentration) of pigs. Livest Sci. 2010;134:146-8.

12. Millet S, Kumar S, De Boever J, Meyns T, Aluwé M, De Brabander D, Ducatelle R. Effect of particle size distribution and dietary crude fibre content on growth performance and gastric mucosa integrity of growingfinishing pigs. Vet J. 2012;192:316-21.

13. Fisher H, Kaufman RH, Hsu HC, Kasziba E, Farmanfarmaian A, Flancbaum LJ. Inhibition of gastric acid secretion in the rat by high calcium. Nutr Res. 1990;10:1441-53.

14. Andrews FM, Buchanan BR, Smith SH, Elliott SB, Saxton AM. In vitro effects of hydrochloric acid and various concentrations of acetic, propionic, butyric, or valeric acids on bioelectric properties of equine gastric squamous mucosa. Am J Vet Res. 2006;67:1873-82.

15. Haaland G, Tyrrell H, Moe P, Wheeler W. Effect of crude protein level and limestone buffer in diets fed at two levels of intake on rumen $\mathrm{pH}$, ammonia-nitrogen, buffering capacity and volatile fatty acid concentration in cattle. J Anim Sci. 1982;55:943-50.

16. Breves G. Nahrungsaufnahme und Speichelsekretion. In: von Engelhardt W, Breves G, Hrsg, editors. Physiologie der Haustiere. 3.Aufl. Stuttgart: Verlag Enke; 2005. p. 332-8

17. Meyer $\mathrm{H}$, Coenen M, Probst D. Futtereinspeichelung und -passage im Kopfdarm des Pferdes. Beiträge zur Verdauungsphysiologie des Pferdes. Japan. 1986;56:171-83.

18. Eckersall PD, Aitchison T, Colquhoun KM. Equine whole saliva: variability of some major constituents. Equine Vet J. 1985;17:391-3.

19. Mößeler A, Wintermann M, Sander SJ, Kamphues J. Effect of grinding and pelleting fed either dry or liquid feed on dry matter and $\mathrm{pH}$ in the stomach of pigs and the development of gastric ulcers. J Anim Sci. 2012;90:343-5.

20. Große Liesner $V$. Investigations on the effects of diet's physical form (particle size, meal vs. pellets) and addition of lignocellulose on the integrity of gastric mucosa in reared piglets [PhD Dissertation med. vet.]. Hannover: Tierärztliche Hochschule Hannover; 2008. http://elib.tihohannover.de/ dissertations/grosseliesnerv_ss08.pdf. Accessed 27 May 2008.

21. Ganter M. Magenulzera beim Schwein aus klinischer Sicht. Deutsche Tierärztl Wochenschr. 1999;106:75.

22. Andrews FM, Nadeau JA. Clinical syndroms of gastric ulceration in foals and mature horses. Equine Vet J Suppl. 1999;29:30-3.

23. Cuddeford D. Artificially dehydrated lucerne for horses. Vet Rec. 1994;29:426-9.

24. Sykes BW, Hewetson M, Hepburn RJ, Luthersson N, Tamzali Y. European college of equine internal medicine-consensus statement: equine gastric ulcer syndrome (EGUS) in adult horses. J Vet Intern Med. 2015;29:1288-99.

25. Naumann C, Bassler R. Methoden der landwirtschaftlichen forschungs- und untersuchungsanstalt biochemische untersuchung von futtermitteln. Methodenbuch III (mit ergänzungslieferungen bis 2004). Darmstadt: Verlag VDLUFA; 1976.

26. Van Soest PJ, Roberston JB, Lewis BA. Methods for dietary fiber, neutral detergent fiber, and nonstarch polysaccharides in relation to animal nutrition. J Dairy Sci. 1991;74:3583-97.

\section{Submit your next manuscript to BioMed Central and we will help you at every step:}

- We accept pre-submission inquiries

- Our selector tool helps you to find the most relevant journal

- We provide round the clock customer support

- Convenient online submission

- Thorough peer review

- Inclusion in PubMed and all major indexing services

- Maximum visibility for your research

Submit your manuscript at www.biomedcentral.com/submit 